\title{
The association between mental-physical multimorbidity and disability, work productivity, and social participation in China: a panel data analysis
}

Tianxin Pan ${ }^{1 *}$ (D), Stewart W. Mercer ${ }^{2}$, Yang Zhao ${ }^{3,4}$, Barbara McPake ${ }^{1}$, Allissa Desloge $^{1}$, Rifat Atun ${ }^{5}$, Emily Susannah Grace Hulse ${ }^{1}$ and John Tayu Lee ${ }^{1,6}$

\begin{abstract}
Background: The co-occurrence of mental and physical chronic conditions (mental-physical multimorbidity) is a growing and largely unaddressed challenge for health systems and wider economies in low-and middle-income countries. This study investigated the independent and combined (additive or synergistic) effects of mental and physical chronic conditions on disability, work productivity, and social participation in China.

Methods: Panel data study design utilised two waves of the China Health and Retirement Longitudinal Study (2011, 2015), including 5616 participants aged $\geq 45$ years, 12 physical chronic conditions and depression. We used a panel data approach of random-effects regression models to assess the relationships between mental-physical multimorbidity and outcomes.

Results: After adjusting for socio-economic and demographic factors, an increased number of physical chronic conditions was independently associated with a higher likelihood of disability (Adjusted odds ratio $(A O R)=1.39$; $95 \% \mathrm{Cl}: 1.33,1.45)$, early retirement $(\mathrm{AOR}=1.37[1.26,1.49])$ and increased sick leave days (1.25 days $[1.16,1.35])$. Depression was independently associated with disability $(A O R=3.78[3.30,4.34])$, increased sick leave days (2.18 days $[1.72,2.77]$ ) and a lower likelihood of social participation (AOR $=0.57[0.47,0.70])$, but not with early retirement $(\mathrm{AOR}=1.24[0.97,1.58])$. There were small and statistically insignificant interactions between physical chronic conditions and mental health on disability, work productivity and social participation, suggesting an additive effect of mental-physical multimorbidity on productivity loss.

Conclusion: Mental-physical multimorbidity poses substantial negative health and economic effects on individuals, health systems, and societies. More research that addresses the challenges of mental-physical multimorbidity is needed to inform the development of interventions that can be applied to the workplace and the wider community in China.
\end{abstract}

Keywords: Multimorbidity, Physical conditions, Mental health conditions, Productivity, Disability, Economic impact, China

\footnotetext{
* Correspondence: tianxin.pan1@unimelb.edu.au

${ }^{1}$ Melbourne School of Population and Global Health, The University of

Melbourne, 207 Bouverie Street, Melbourne, Victoria 3010, Australia

Full list of author information is available at the end of the article
}

C C The Author(s). 2021 Open Access This article is licensed under a Creative Commons Attribution 4.0 International License, which permits use, sharing, adaptation, distribution and reproduction in any medium or format, as long as you give appropriate credit to the original author(s) and the source, provide a link to the Creative Commons licence, and indicate if changes were made. The images or other third party material in this article are included in the article's Creative Commons licence, unless indicated otherwise in a credit line to the material. If material is not included in the article's Creative Commons licence and your intended use is not permitted by statutory regulation or exceeds the permitted use, you will need to obtain permission directly from the copyright holder. To view a copy of this licence, visit http://creativecommons.org/licenses/by/4.0/ The Creative Commons Public Domain Dedication waiver (http://creativecommons.org/publicdomain/zero/1.0/) applies to the data made available in this article, unless otherwise stated in a credit line to the data. 


\section{Background}

Non-communicable diseases (NCDs) are the leading cause of global disease burden, contributing to approximately three-quarters of total deaths in 2017 [1], with over $85 \%$ of premature mortality occurring in low-and middle-income countries (LMICs) [2]. The prevalence of multimorbidity, defined as having two or more coexisting chronic conditions, is likely to increase given increasing exposure to risk factors (such as obesity, smoking, physical inactivity) and the ageing population in many settings [3-7]. China, the most populous country and the second-largest economy in the world, has seen rapid demographic and epidemiological transitions over the last few decades. By 2050, the projected proportion of the older population, aged 60 years and over, will dramatically increase to $35.1 \%$ from $16.2 \%$ in 2017 [8]. NCDs represent the most significant share of the burden of disease in China, comprising nearly $90 \%$ of total deaths, and $83 \%$ of total Disability-Adjusted Life Years (DALYs) lost in 2017 [9]. The prevalence of multimorbidity has been increasing rapidly in China [10-12]. A recent nationally representative Chinese study, based on 11 physical chronic conditions, found that the prevalence of multimorbidity increased from $51 \%$ in those aged $50-54$ years to $71 \%$ for those aged 75 years and above [12]. Findings from the China Mental Health Survey suggested that the weighted prevalence of mental disorders among Chinese adults was $9.3 \%$ in 2013, and most mental disorders have become more common over the past 30 years [13]. The rising burden of chronic conditions and mental disorders poses a substantial threat to household welfare through increased out-of-pocket (OOP) health expenditures and reduced productivity and income. It also poses challenges to the health system in providing a combination of preventive, curative and supportive care services, as well as to the social health insurance schemes in providing financial protection for affected individuals and households. The current health system is treatment-focused and volume-driven, leading to high health expenditures [14]. China has achieved close to universal population coverage through three basic medical insurance schemes (Urban Employee Medical Insurance Scheme, Urban Residents Medical Insurance Scheme and New Rural Cooperative Medical Scheme), but the health service benefit package and patient financial reimbursements of these schemes are incomplete [15]. Patients with chronic conditions and multimorbidity are less protected and have a higher probability of incurring catastrophic health expenditures $[12,16,17]$. Also, there exist inequalities in accessing and using health care and receiving financial protection between rural and urban populations $[18,19]$.

Multimorbidity can involve different patterns of physical and mental chronic conditions, combinations, or clusters. Evidence from a meta-analysis suggests that the association between physical and mental chronic conditions can be bi-directional [20]. A recent study in Scotland found that among patients with multimorbidity, $4 \%$ had mental multimorbidity, while $40 \%$ had both physical and mental multimorbidity which was the most common type in those aged 55 years and less [21]. Despite the growing prevalence of mental-physical multimorbidity (i.e. the co-occurrence of mental and physical chronic conditions) in LMICs, there is little attention given to the combined impact of mental-physical multimorbidity as opposed to physical-only or mental-only chronic conditions.

The economic impact of mental-physical multimorbidity, particularly their implication on productivity is an area of emerging research inquiry. To date, the evidence on the effect of mental-physical multimorbidity is mostly from high-income countries (HICs). Evidence from HICs pointed out that multimorbidity imposes substantial economic costs, i.e. patients with multimorbidity incur large medical expenditures $[22,23]$ and are more likely to be absent from work [24-26]. The literature on the economic impact of mental-physical multimorbidity is relatively sparse in a LMIC setting, where the prevalence and pattern of mental-physical multimorbidity, and the ability of its health care system and social support service (such as health insurance, unemployment insurance, sick leave benefits) in mitigating the potential combined impact of physical illness and mental disorder on health and economic outcomes might be different. A recent systematic review that examined the effect of multimorbidity on productivity [27], showed that almost all previous studies were from high-income countries except one from Egypt [28]. However, the study in Egypt did not examine the combined effect of mental and physical chronic conditions on work productivity. There are no studies in China that have examined the impact of mental-physical multimorbidity on disability, work productivity, and the economy. To fill this important evidence gap, we present the first study that uses nationally-representative panel data from China, to examine (1) the independent effects of mental and physical chronic conditions on disability, work productivity, and social participation in China, and (2) the combined effects of mental-physical multimorbidity being additive or synergistic, given the independent effects of each type of chronic condition.

\section{Method}

\section{Sample and data}

We used data from the China Health and Retirement Longitudinal Study (CHARLS), which collects information on individuals aged 45 years or older in China and their household characteristics. The survey data included 
measures of physical and psychological health, demographics, socio-economic status (SES), and productivity outcomes [29]. Notably, unlike most household surveys from LMIC settings which solely rely upon self-reported data, CHARLS collects a set of biomarkers including measured blood pressure, and collects whole blood samples of all respondents who gave informed consent. At the time of our analysis, there were three waves of data (2011, 2013 and 2015) that are publicly available. However, the whole blood sample was only collected in 2011 and 2015.

We utilised two waves (2011 and 2015) of CHARLS data to construct a balanced sample. The baseline sample comprised of 17,708 individuals, of which 9971 also had data on blood pressure and the blood sample. Among then, there were 5751 individuals who remained in the 2015 follow-up wave and had their blood pressure measured and blood sample taken. After removing individuals with missing values for key independent variables on socio-demographic characteristics and weighting variables $(2.3 \%)$, our final balanced sample consisted of 5616 individuals from each wave, thus a total of 11,232 pooled sample observations.

For the purpose of the study, we examined disability in an all adult sample aged 45 and older. We examined work productivity outcomes among respondents aged below 60 years, based on the mandatory retirement age for male white-collar workers in China [30]. We conducted sensitivity analyses using cut-off ages at 55 years and 65 years respectively, given that the mandatory retirement age for female white-collar workers is 55 years and the possibilities that people might continue working after the mandatory retirement age. We analysed social participation outcome among respondents who were not in employment or in the labour force (Sample flowchart is presented in Figure A1, Additional file 1).

\section{Variables}

\section{Key predictors (multimorbidity and depression)}

A total of 12 physical chronic conditions were used to measure physical multimorbidity, including hypertension, diabetes and dyslipidaemia which were objectively measured based on biomarkers and blood sample information, and nine self-reported diagnosed physical chronic conditions (heart disease, stroke, cancer, chronic lung disease, digestive disease, liver disease, kidney disease, arthritis and asthma). In CHARLS, blood pressure was measured through a physical examination accompanying the survey. The systolic and diastolic blood pressure were measured and recorded three times using an electronic sphygmomanometer. For blood sample collection, three tubes of venous blood were collected from each respondent who gave consent by medicallytrained staff from the Chinese Center for Disease
Control and Prevention, based on a standard protocol [31]. In this study, individuals were defined as hypertensive if they had 1) a systolic blood pressure (SBP) $\geq 140$ $\mathrm{mmHg}$; and/or 2) a diastolic blood pressure (DBP) $\geq 90$ $\mathrm{mmHg}$; and/or 3) taking anti-hypertension medicines at the time of the survey [32]. Diabetes was defined by 1) a fasting plasma glucose level of $\geq 126 \mathrm{mg} / \mathrm{dL}(7.0 \mathrm{mmol} /$ L); and/or 2) HbA1c concentration of $\geq 6.5 \%$; and/or 3) receiving insulin treatment and/or taking medication for raised blood sugar [33, 34]. Dyslipidaemia was defined by 1 ) total cholesterol (TC) $\geq 240 \mathrm{mg} / \mathrm{dL}(6.22 \mathrm{mmol} / \mathrm{L})$; and/or 2) low-density lipoprotein cholesterol (LDL-C) $\geq$ $160 \mathrm{mg} / \mathrm{dL}$ (4.14 mmol/L); and/or 3) high-density lipoprotein cholesterol $(\mathrm{HDL}-\mathrm{C})<40 \mathrm{mg} / \mathrm{dL}(1.04 \mathrm{mmol} / \mathrm{L})$; and/or 4) triglyceride (TG) $\geq 200 \mathrm{mg} / \mathrm{dL}(2.26 \mathrm{mmol} / \mathrm{L})$; and/or 5) taking anti-dyslipidaemia medication [35, 36]. We counted the number of physical chronic conditions reported for each participant to identify those with physical multimorbidity.

We used the presence of depression as an indicator of the presence of a mental health condition. Depression was identified using a self-reported CES-D10 score, and an individual with a score greater than ten was identified as having depression [37].

Respondents who had both depression and physical chronic conditions were defined as having mentalphysical multimorbidity in this study.

\section{Dependent variables}

The instrumental activity of daily living (IADL) and the activity of daily living (ADL) were used to evaluate the self-reported functional disability. The abilities such as doing housework, cooking, taking medicine, shopping, and taking care of finances, which are required for living independently in the community, were used to assess the IADL. ADL refers to daily self-care tasks including eating, dressing, taking a bath, getting in and out of bed, using the toilet, and maintaining continence of urine and faeces [37]. For both the IADL and the ADL items, respondents were given a code of 1 if they reported any difficulties in any items and were identified as IADLdisability and or ADL-disability, respectively.

We examined two work productivity outcomes: (1) early retirement, which is a binary variable that indicates whether the respondent was retired at the time of the interview, and (2) the number of days missed due to sick leave at their primary job, which was calculated based on the questions "How many days of work did you miss last year due to a health problem" and the respondent's primary work type.

Engaging in productive activities is associated with the well-being of middle-aged and older adults and important for performing valued functions to families and society [38]. Following the literature, we used an indicator of 
social participation to measure productive activities among older adults $[39,40]$. Social participation was derived from the question "Have you done any of these activities in the last month." A code of 1 indicates that the respondent participates in any one of the following social activities: interacting with friends; playing Mah-jong (a tile-based game developed and widely played in China), chess, or going to a community club; going to a sporting event or participating in a social group; taking part in a community-related organisation; taking part in voluntary or charity work, and attending an educational or training course.

\section{Covariates}

The following variables were included as covariates: year, age, gender, marital status (married and partnered, and otherwise), residency (rural or urban), Hukou (household registration system) status (agricultural Hukou or non-agricultural Hukou), geographical region (east China, middle China, west China, northeast China), family size, education (illiterate, primary school, secondary school, college and above), SES quartile (using household consumption expenditures per capita as a proxy of permanent income, Q1 being the poorest and Q4 being the richest), and work type (farming, formally employed, self-employed, family business, unemployed, retired, never worked). The included socio-demographic characteristics are those demonstrated to be associated with disability and productivity outcomes in the literature $[3,24,27,41]$.

\section{Statistical analyses}

We summarised the mean and proportion of outcomes by the number of physical chronic conditions and the presence of depression. We used a panel data approach of random-effects logistic regression to assess the relationships between physical chronic conditions, depression and probability of reporting disability, early retirement and social participation. We applied a generalized linear model with gamma distribution and log link function to assess the relationship between physical chronic conditions, depression and the number of sick leave days, because the data on the sick leave days were highly skewed [42]. We reported the adjusted odds ratio (AOR) from logistic models and the exponentiated form of coefficients from log-gamma models with $95 \%$ confidence intervals $(\mathrm{CI})$.

We fitted additional models examining whether the combined effect of both physical chronic conditions and depression was more or less than that expected (synergistic or antagonistic), given the independent burden of each (i.e. the additive effect). This was achieved by including two-way interaction terms between physical chronic conditions and depression in our regression model. A positive coefficient for the interaction terms (odds ratio $>1$ in logistic regression models of disability, early retirement, and social participation and positive coefficients in the generalized linear model of sick leave days) suggests that the combined effect of two conditions is synergistic, more than the additive effect of each one of them independently. Furthermore, we tested for linearity of the number of physical chronic conditions and added a quadratic term for the number of physical chronic conditions. Predicted values of disabilities, work productivity, and social participation outcomes were estimated using coefficients from regression models. All statistical analyses were conducted using STATA 15.0. $P$-values of less than 0.05 were considered as statistically significant.

\section{Results}

\section{Descriptive analysis}

We analysed data from 5616 respondents. Table A1 presents the respondents' socio-economic and demographic characteristics (see Additional file 2). The median age of the respondents was 62 years old (Interquartile range (IQR) $=56-68$ ) in 2015. There was a slightly higher percentage of female $(54 \%)$ than male respondents. The majority of the respondents were married (85\%) and resided in rural areas (67\%). Only $29 \%$ of the respondents had attained a level of education higher than primary school, $50 \%$ of the respondents engaged in farming, and $34 \%$ of the respondents were retired.

The prevalence of multimorbidity increased from $69 \%$ in 2011 to $76 \%$ in 2015 . While this may be a result of ageing (Table A1), the increase in prevalence of multimorbidity was mainly driven by presence of two or more physical chronic conditions (increased from 34 to 43\%) rather than depression (34 to 33\%). We also explored patterns of multimorbidity, and we found that among people with multimorbidity in $2015,57 \%$ of them only had physical multimorbidity (increased from 50\% in 2011), and $43 \%$ of them had mental-physical multimorbidity (dropped from $50 \%$ in 2015).

The unadjusted mean or proportion of disability and productivity outcomes by type of multimorbidity are reported in Table A2 (see Additional file 3). The adjusted associations are presented blow.

We tested the interactions between physical multimorbidity and mental health, however the effects were small and not statistically significant. We tested for linearity of the number of physical chronic conditions, and the quadratic term for the number of physical chronic conditions were small and not statistically significant. We therefore only present the more parsimonious model without interactions or a quadratic term as the main results (Table 1). The results from the models including 
Table 1 Association between multimorbidity and disability, work productivity and social participation

\begin{tabular}{|c|c|c|c|c|c|}
\hline & \multicolumn{2}{|l|}{ Disability } & \multicolumn{2}{|l|}{ Work productivity } & \multirow{2}{*}{$\begin{array}{l}\text { Social participation } \\
\text { Social participation } \\
(n=3301) \\
\text { AOR }(95 \% \mathrm{Cl})\end{array}$} \\
\hline & $\begin{array}{l}\text { Difficulties in IADLs } \\
(n=11,116) \\
\text { AOR }(95 \% \mathrm{Cl})\end{array}$ & $\begin{array}{l}\text { Difficulties in ADLs } \\
(n=11,162) \\
\text { AOR }(95 \% \mathrm{Cl})\end{array}$ & $\begin{array}{l}\text { Early retirement } \\
(n=5261) \\
\text { AOR }(95 \% \mathrm{Cl})\end{array}$ & $\begin{array}{l}\text { Number of days of } \\
\text { sick leave }(n=4141) \\
\text { mean }(95 \% \mathrm{Cl})\end{array}$ & \\
\hline Number of physical NCDs & $1.27(1.22,1.32)$ & $1.39(1.33,1.45)$ & $1.37(1.26,1.49)$ & $1.25(1.16,1.35)$ & $1.06(1.00,1.13)$ \\
\hline Depression & $3.59(3.16,4.07)$ & $3.78(3.30,4.34)$ & $1.24(0.97,1.58)$ & $2.18(1.72,2.77)$ & $0.57(0.47,0.70)$ \\
\hline 2015 & $1.21(1.08,1.35)$ & $1.46(1.29,1.66)$ & $1.58(1.28,1.96)$ & $1.07(0.85,1.35)$ & $0.98(0.82,1.17)$ \\
\hline \multicolumn{6}{|l|}{ Age group (ref: 45-54) } \\
\hline Age 55-64 & $1.43(1.21,1.69)$ & $1.67(1.39,2.02)$ & $1.96(1.54,2.49)$ & $0.92(0.72,1.17)$ & $0.92(0.68,1.24)$ \\
\hline Age 65-74 & $2.21(1.82,2.67)$ & $2.49(2.02,3.08)$ & & & $0.94(0.68,1.29)$ \\
\hline Age $75+$ & $4.08(3.14,5.30)$ & $3.85(2.89,5.12)$ & & & $0.66(0.45,0.97)$ \\
\hline Female gender & $1.46(1.27,1.67)$ & $1.19(1.02,1.38)$ & $4.60(3.39,6.26)$ & $0.89(0.70,1.13)$ & $1.06(0.85,1.32)$ \\
\hline Married & $1.03(0.86,1.23)$ & $0.97(0.80,1.18)$ & $0.97(0.59,1.58)$ & $1.36(0.85,2.19)$ & $0.74(0.57,0.95)$ \\
\hline Agricultural hukou & $1.09(0.91,1.32)$ & $1.18(0.97,1.44)$ & $0.32(0.23,0.45)$ & $1.33(0.92,1.92)$ & $0.48(0.37,0.62)$ \\
\hline Rural residency & $1.41(1.21,1.63)$ & $1.23(1.04,1.44)$ & $0.24(0.18,0.33)$ & $1.25(0.97,1.63)$ & $1.19(0.95,1.50)$ \\
\hline \multicolumn{6}{|l|}{ Region (ref:east China) } \\
\hline Middle China & $1.20(1.02,1.42)$ & $1.88(1.57,2.25)$ & $0.81(0.59,1.12)$ & $1.11(0.84,1.48)$ & $0.93(0.73,1.20)$ \\
\hline West China & $1.12(0.95,1.32)$ & $1.14(0.95,1.37)$ & $0.58(0.42,0.81)$ & $1.17(0.89,1.55)$ & $0.66(0.51,0.86)$ \\
\hline Northeast China & $1.78(1.37,2.31)$ & $1.73(1.30,2.32)$ & $1.11(0.66,1.86)$ & $1.35(0.82,2.24)$ & $0.76(0.53,1.10)$ \\
\hline \multicolumn{6}{|c|}{ Family size (ref: 1, 2 members) } \\
\hline 3-4 members & $1.07(0.93,1.23)$ & $1.06(0.91,1.23)$ & $1.01(0.77,1.33)$ & $0.90(0.69,1.17)$ & $0.95(0.77,1.18)$ \\
\hline 4+ members & $1.22(1.04,1.44)$ & $0.95(0.79,1.14)$ & $1.51(1.09,2.10)$ & $1.06(0.78,1.46)$ & $1.08(0.83,1.40)$ \\
\hline \multicolumn{6}{|l|}{ Education level (ref:illiterate) } \\
\hline Primary & $0.60(0.51,0.71)$ & $0.75(0.63,0.90)$ & $0.83(0.58,1.19)$ & $0.79(0.58,1.07)$ & $1.27(0.98,1.65)$ \\
\hline Secondary & $0.48(0.39,0.58)$ & $0.61(0.49,0.75)$ & $1.20(0.86,1.69)$ & $0.79(0.59,1.08)$ & $1.40(1.04,1.87)$ \\
\hline Tertiary & $0.38(0.28,0.52)$ & $0.43(0.31,0.60)$ & $0.88(0.56,1.36)$ & $0.76(0.52,1.12)$ & $2.79(1.84,4.25)$ \\
\hline \multicolumn{6}{|c|}{ HH consumption per capita (ref:Q1) } \\
\hline Q2 & $1.05(0.89,1.22)$ & $0.99(0.84,1.18)$ & $0.84(0.60,1.18)$ & $1.13(0.83,1.55)$ & $1.18(0.90,1.54)$ \\
\hline Q3 & $1.06(0.90,1.25)$ & $0.89(0.75,1.06)$ & $1.10(0.79,1.53)$ & $1.03(0.76,1.40)$ & $1.09(0.83,1.42)$ \\
\hline Q4 (richest) & $1.11(0.94,1.32)$ & $1.00(0.83,1.20)$ & $1.68(1.21,2.34)$ & $1.49(1.07,2.07)$ & $1.30(0.99,1.70)$ \\
\hline \multicolumn{6}{|l|}{ Work type (ref:farming) } \\
\hline Formally Employed & & & & $0.32(0.23,0.44)$ & \\
\hline Self-employed & & & & $0.65(0.43,0.99)$ & \\
\hline Family business & & & & $1.30(0.63,2.70)$ & \\
\hline
\end{tabular}

The regression model is adjusted for all socio-demographic covariates. Bold font indicate significance at $5 \%$ level

Generalized linear model with gamma distribution and log link function is used to estimate the association between multimorbidity and the number of days of sick leave at main job. Random-effect logistic models are used for other outcomes

$A O R$ Adjusted odds ratio, $\mathrm{Cl}$ Confidence interval

interactions are presented in Table A3 (see Similarly, an increasing number of physical chronic conAdditional file 4). ditions (AOR $=1.39,95 \% \mathrm{CI}: 1.33,1.45)$, and the presence of depression $(\mathrm{AOR}=3.78,95 \% \mathrm{CI}$ : $3.30,4.34)$ was

Mental-physical multimorbidity and disability

Table 1 shows the adjusted odd ratios for the associations between mental-physical multimorbidity and disability. An increasing number of physical chronic conditions $(\mathrm{AOR}=1.27,95 \% \mathrm{CI}: 1.22,1.32)$, and the presence of depression (AOR $=3.59,95 \% \mathrm{CI}: 3.16,4.07$ ) was associated with a higher risk of IADL disability. also associated with a higher risk of ADL disability.

The predicted probability of reporting limitations in IADLs increased from 0.07 for males and from 0.10 for females without any physical chronic conditions and depression to 0.36 for males and 0.45 for females with more than two physical chronic conditions and depression respectively (Fig. 1a). Similarly, compared 


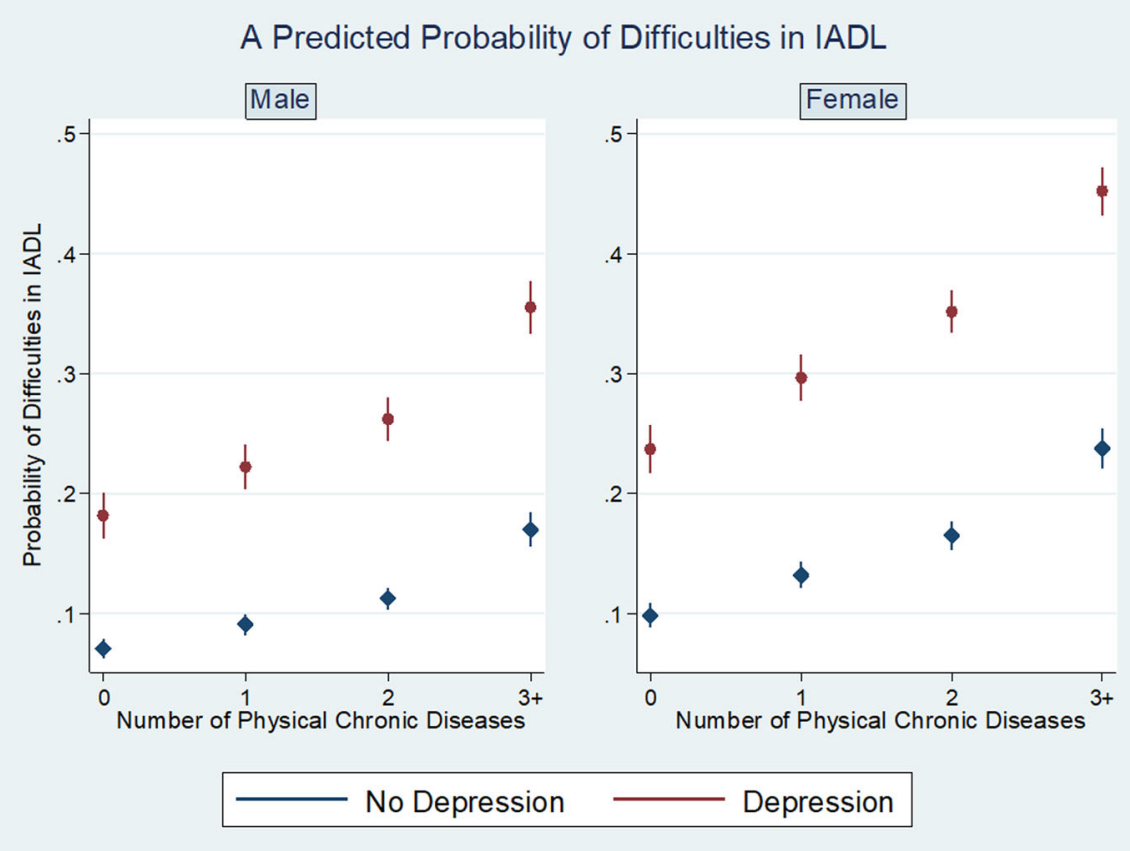

B Predicted Probability of Difficulties in ADL
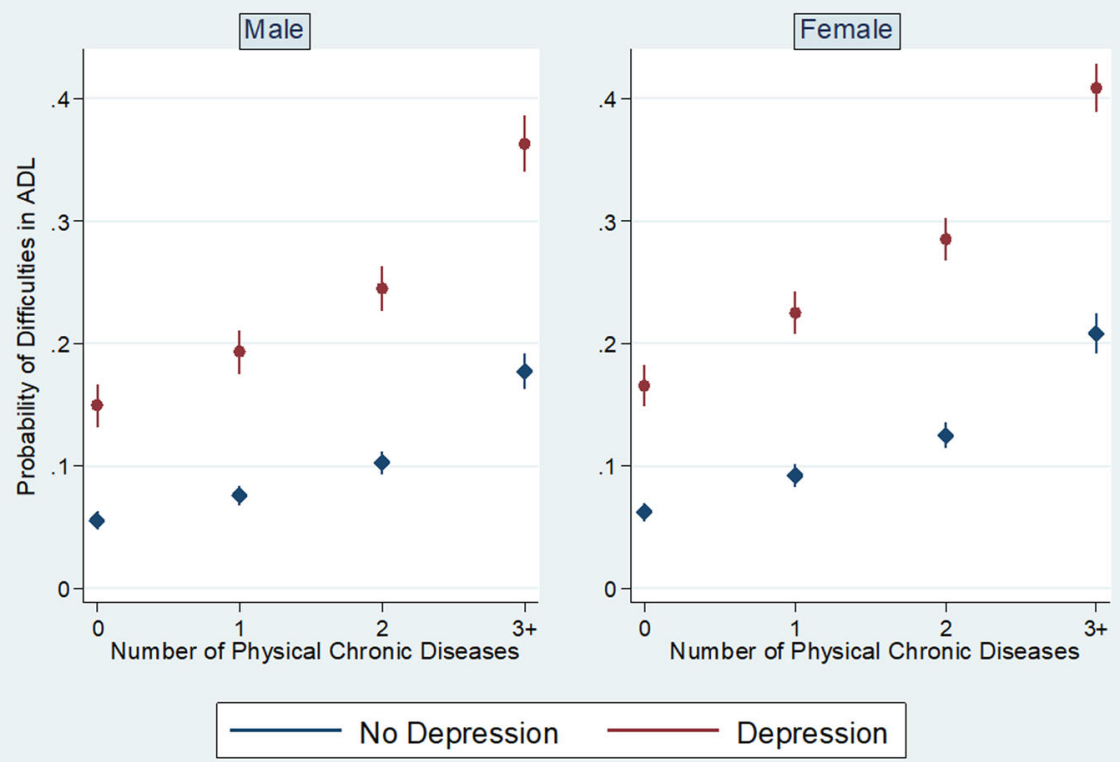

Fig. 1 The associations between mental-physical multimorbidity and disability, by gender. a Predicted probability of difficulties in instrumental activity of daily living (IADL) by the number of physical chronic conditions and depression, stratified by gender group, China Health and Retirement Longitudinal Study, 2011 and 2015. Random-effect logistic models are used. Adjusted for all socio-demographic covariates. b Predicted probability of difficulties in activity of daily living (ADL) by the number of physical chronic conditions and depression, stratified by gender group, China Health and Retirement Longitudinal Study, 2011 and 2015. Random-effect logistic models are used. Adjusted for all socio-demographic covariates

to those without physical chronic conditions and depression, the predicted probability of reporting limitations in ADLs was much higher for individuals with more than two physical chronic conditions and with depression (Fig. 1b).

\section{Mental-physical multimorbidity and work productivity}

Table 1 also shows that among respondents aged under 60 years, early retirement was associated with an increasing number of physical chronic conditions $(\mathrm{AOR}=1.37$, 95\% CI: 1.26, 1.49), but not associated with depression 
$(\mathrm{AOR}=1.24,95 \% \mathrm{CI}: 0.97,1.58)$. The odds ratio of reporting early retirement was nearly five times higher for females compared to males $(\mathrm{AOR}=4.60,95 \% \mathrm{CI}$ : $3.39,6.26)$. We found that an increasing number of physical chronic conditions was independently associated with an increased number of sick leave days (mean number of days $=1.25,95 \%$ CI: 1.16, 1.35). The presence of depression was also associated with an increased number of sick leave days (mean number of days $=2.18$, 95\% CI: 1.72, 2.77). Depression was associated with a higher number of sick leave days than one physical chronic condition. In addition, respondents who engaged in the formal sectors or were self-employed were associated with fewer sick leave days compared to those engaged in farming. When we using a sample of respondents under 55 years and using a sample of respondents under 65 years, the results were fairly similar to our main results (see Table A4 in Additional file 5).

Among the working-age population, the predicted probability of reporting early retirement increased from 0.06 for males and from 0.15 for females without any physical chronic conditions and depression to 0.15 for males and 0.30 for females with more than two physical chronic conditions and depression respectively (Fig. 2a). Similarly, compared to those without physical chronic conditions and depression, female respondents who had depression and had more than two physical chronic conditions had more extended sick leave (33.51 days vs 4.62, Fig. 2b), compared to males without physical chronic conditions and depression.

\section{Mental-physical multimorbidity and social participation}

We found that the presence of depression was associated with a substantial decrease in the likelihood of social participation in those who were not working $(\mathrm{AOR}=$ 0.57, 95\% CI: 0.47, 0.70). We also found a small but statistically significant association between an increasing number of physical chronic conditions and likelihood of social participation (AOR $=1.06,95 \% \mathrm{CI}: 1.00,1.13$ ). As shown in Fig. 3, the predicted probability of social participation was 0.55 for males ( 0.54 for females) without physical chronic conditions and without depression, and dropped to 0.48 for males ( 0.46 for females) with more than two physical conditions and depression.

\section{Discussion}

This study found that the prevalence of multimorbidity was 76\% among Chinese aged over 45 years in 2015. Among them, $57 \%$ had two or more physical chronic conditions, and $43 \%$ had both mental and physical chronic conditions. Physical chronic conditions were independently associated with a higher likelihood of disability, early retirement, increased sick leave days and participation in social activity. The presence of depression was also independently associated with disability, increased sick leave days and a lower likelihood of social participation. Mental-physical multimorbidity showed additive effects on disability, work loss and social participation.

We found the overall prevalence of multimorbidity in 2015 to be 76\%, which was higher than the results from other studies using either the same or similar dataset $[11,12,43,44]$. For example, Zhao et al. used the same dataset and found the prevalence of multimorbidity, physical multimorbidity and mental-physical multimorbidity in 2015 to be 62,39 and $32 \%$ respectively [12, 43]. The main reason is that these studies used self-reported measures of physical chronic conditions, whereas our study used objective measures of diabetes and dyslipidaemia based on a whole blood sample. Studies that used nationally-representative sample of screening or surveillance data have shown that the prevalence of hypertension, diabetes and dyslipidaemia were high among Chinese adults (45, 12 and 43\% respectively), but awareness rates were very low, with only one-third of patients being aware of their conditions [34, 45-47].

Our findings are generally in line with those of a small number of previous studies from HICs, which showed that physical chronic conditions and depression were independently associated with the number of sick leave days, and the effect of depression on work productivity loss was larger compared to an increased number of physical chronic conditions $[24,41]$. The evidence on the combined effect of mental-physical multimorbidity on work productivity loss (including absenteeism and/or presenteeism) is mixed from HICs and varies across the type of physical chronic conditions, productivity outcome considered and study sample. Several studies reported that mental-physical multimorbidity led to a mainly additive increase in work loss. For example, Demyttenaere et al. used a general population sample from six European countries and found that respondents with depression only and those with painful physical symptoms only reported 4.5 and 3.6 work-loss days respectively, whereas respondents with both conditions reported 9.4 work-loss days per month [24]. Buist-Bouwman et al. used a general population sample aged between 18 and 64 from the Netherlands and examined the independent and combined effects of different physical and mental conditions on work loss. They found that mental disorders led to significantly more work-loss days than hypertension only ( 28.3 days vs 5.6 days) and asthma only (18.6 days vs 5.4 days), and was comparable with diseases of the digestive system only ( 14.2 days vs 14.1 days) in the past 12 months. The effect of mental-physical multimorbidity was 


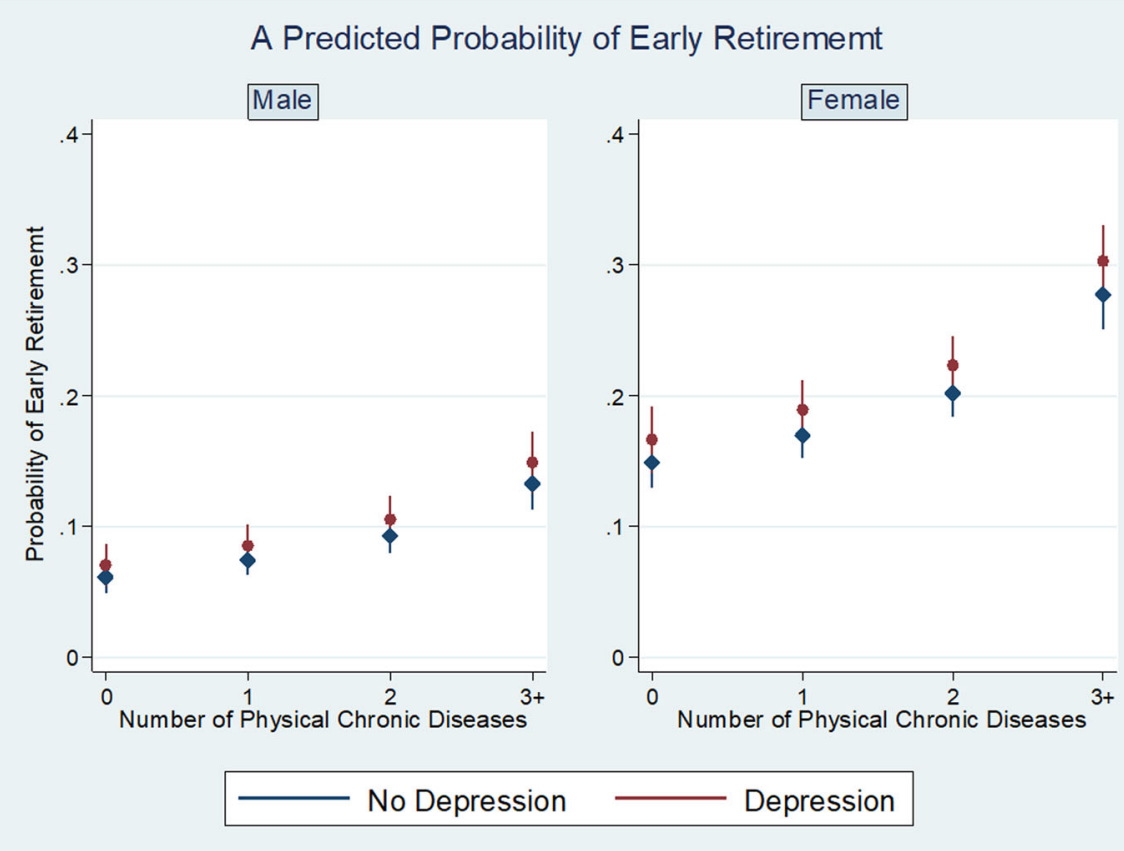

B Predicted Days of Sick Leave

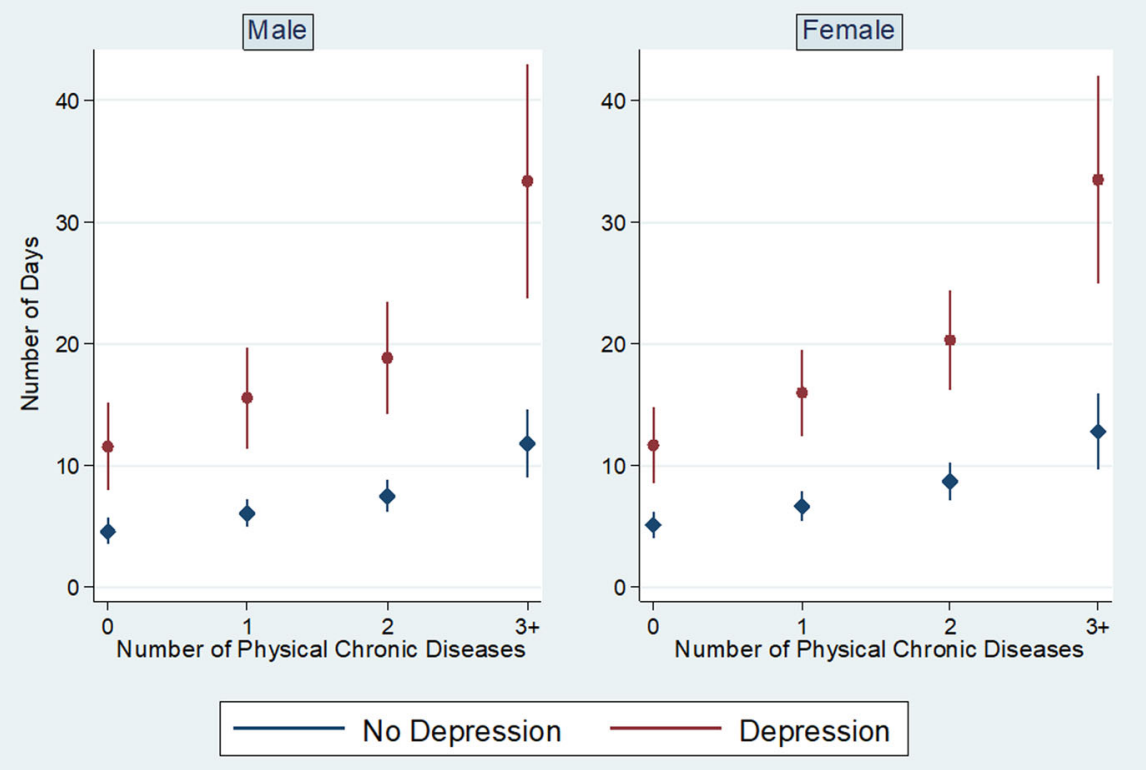

Fig. 2 The associations between mental-physical multimorbidity and work productivity, by gender. a Predicted probability of early retirement by the number of physical chronic conditions and depression, stratified by gender group, China Health and Retirement Longitudinal Study, 2011 and 2015. Random-effect logistic model is used. Adjusted for all socio-demographic covariates. $\mathbf{b}$ Predicted number of sick leave days by the number of physical chronic conditions and depression, stratified by gender group, China Health and Retirement Longitudinal Study, 2011 and 2015. Generalized linear model with gamma distribution and log link function is used. Adjusted for all socio-demographic covariates

additive for asthma (18.6 days) and digestive system diseases (33.3 days) but synergistic for hypertension (28.3 days). However, an Australian study using a sample of the working population and WHO Health and Productivity Questionnaire found synergistic effects on absenteeism for some physical conditions (such as cancer, high cholesterol) when co-morbid with psychological distress. They also found synergistic and larger effects on presenteeism than absenteeism for every physical conditions included in their study when co-morbid with psychological distress [25]. 
Predicted Probability of Social Participation

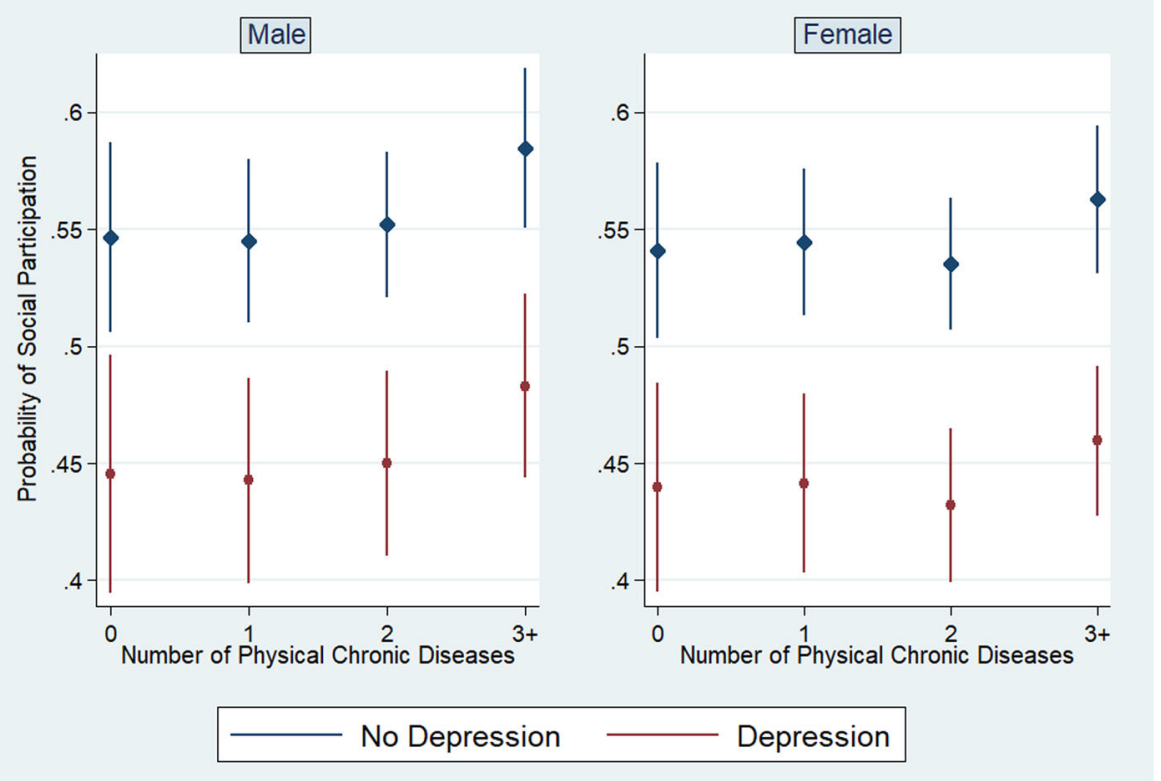

Fig. 3 The associations between mental-physical multimorbidity and social participation, by gender. Predicted probability of social participation by the number of physical chronic conditions and depression, stratified by gender group, China Health and Retirement Longitudinal Study, 2011 and 2015. Random-effect logistic models are used. Adjusted for all socio-demographic covariates

To date, there have been no studies exploring the combined effect of mental-physical multimorbidity on productivity in China or other LMICs. We add to the existing literature that the combined effects are mainly additive in China. One distinction between LMICs and HICs is that a higher number of people engaged in the informal sector such as farming in LMICs $[48,49]$. Our analysis showed that compared to people who work in the formal sector, those engaged in farming were more likely to have an increased number of sick leave days. However, there existed the possibility that employees in the formal sectors may show up for work while sick, which can lead to presenteeism [50]. Furthermore, we found that respondents with physical chronic conditions were more likely to retire early, and the effects were substantially larger on females compared to males. This is in line with studies from HICs, which showed similar findings that females with multimorbidity were more likely to transition out of a full-time job [51].

Consistent with earlier studies examining the effect of multimorbidity on disability in both LMICs and HICs settings [3, 52-54], our study found that both physical multimorbidity and depression was positively associated with disability among Chinese mid-aged and elderly population. We found that the combined effect of the co-existence of mental and physical chronic conditions on IADL and ADL was additive of each independently. However, evidence on the combined effects on disability is rather mixed, with additive effects $[3,55,56]$ and synergistic effects $[53,57]$ both being found in literature. These studies differ in the type of physical chronic conditions included and disability measure used.

Our findings on the negative association between depression and social participation align with other studies from HICs [58]. However, we also found a small but positive association between an increasing number of physical chronic conditions and social participation, whereas most existing studies showed physical chronic conditions to be associated with lower participation in social activities. One explanation might be attributed to the types of activities which were considered as social participation in the CHARLS survey, which varied widely in terms of the physical ability needed. An alternative explanation is that there are other important determinants, such as education that may have a greater impact on social participation [58].

Recent literature reviews has pointed out that the literature on multimorbidity and work productivity loss is relatively sparse in LMICs [23, 27]. To the best of our knowledge, this is the first study that examined the impact of mental-physical multimorbidity across disability, work productivity, and social participation outcomes using a robust panel study design in China. However, the study has several caveats. First relates to the use of retrospective self-reported data and potential measurement error. We used a self-reported 
number of sick leave days which may open to recall bias, particularly among those working in the informal sector. We used objective measures of hypertension, diabetes and dyslipidaemia; however other physical chronic conditions still relied on self-reported data which may lead to underestimation particularly among those from lower SES and educational backgrounds and rural areas due to restricted access to health care services [17]. Future work that links household survey data with surveillance systems or hospital administrative data could provide high-quality information on patient health and the character of the disease itself, thus help to address the measurement error associated with self-reported data. Second, reverse causality may exist in the relationship between mental-physical multimorbidity on work productivity and social participation. For instance, early retirement has impacts on mental health. People move to retirement early show improved subjective health status and mental health $[59,60]$, on the other hand, people who experience reduced work hours and job loss tend to have poor mental health $[59,61]$. Third, the presence of unobserved factors of multimorbidity and work and social productivity measures, such as personality, can bias our estimation. The availability of panel data can normally help attenuate the effects of unobserved heterogeneity at the individual level by applying a fixed-effects model. However, by applying fixed-effects model we cannot identify the impact of factors of interest that lack variation over time, such as gender and education. We acknowledge that our results remain subject to bias in terms of measurement error and omitted variables, and our study does not infer causation and further studies are needed to look at the causal effect of multimorbidity on productivity loss. Future research would benefit from more extended panels, which enables observations of the onset of mental-physical multimorbidity and its longterm impact on productivity loss, and vice versa. Fourth, we have used a count of physical chronic conditions as a measure of physical multimorbidity, which did not account for different types and the levels of severity of the chronic conditions. In addition, CHARLS does not contain other measures on mental health conditions except for depression, so our estimated effects of having depression may also capture a wider effect of mental health conditions. The literature shows that the combined effect of mental-physical multimorbidity on disability and work productivity differ across types of conditions [24, 41, 53]. Future research that considers different combinations of chronic conditions and include more mental conditions can enrich our understanding of the economic impact of mental-physical multimorbidity.
Lastly, our estimation on the association between multimorbidity and work productivity was among respondents aged between 45 and 60 years. Due to the fact that CHALRS only focused on people aged 45 years and above, we were not able to estimate the effects of multimorbidity on work productivity on a younger population, where the magnitude of the effects might be different $[62,63]$. There is a need for further research on the economic impact in younger population, particularly from LMICs [4].

Our findings have important implications for public health policy and research. The findings that more than $40 \%$ of respondents with multimorbidity had both mental and physical chronic conditions in China highlight the importance to address the co-existing mental-physical multimorbidity. The healthcare system in China is more hospital-centric and with a single disease model, rather than a strong primary healthcare system led by generalist physicians working with multi-disciplinary teams. Efficient management of mental-physical multimorbidity needs an integrated care model and implement interventions in different settings, including clinical settings, community and workplace. Protecting the physical health of people with mental illness and protecting the mental health of people with physical chronic conditions should be considered a priority to reduce the economic impact of mental-physical multimorbidity to individuals, employers and the whole society, particularly in low-income and middle-income settings. Public health strategies aimed at addressing mental-physical multimorbidity in the workplace should be seen as an 'investment' rather than a cost, with the costs of the intervention likely to be 'offset' by long-term cost savings achieved from improved health and productivity [64]. In China, these interventions may include supporting a healthy work environment, promoting workplace physical activity, and providing on-site counselling services as well as resilience and coping skills training [65]. More research that addresses the challenges of mental-physical multimorbidity is needed to inform the development of interventions that can be applied to the workplace and the wider community in China, and effectiveness trials in workplace samples are needed to evaluate the cost-effectiveness of interventions to screen and manage mental-physical multimorbidity among employees.

\section{Conclusion}

Mental-physical multimorbidity poses substantial negative health and economic effects on individuals, health systems, and societies. More research that addresses the challenges of mental-physical multimorbidity is needed to inform the development of interventions that can be applied to the workplace and the wider community in China. 


\section{Supplementary Information}

The online version contains supplementary material available at https://doi. org/10.1186/s12889-021-10414-7.

Additional file 1: Figure A1. Sample Flowchart. Figure A1 presents the sample flowchart, and the number of observations for each outcome in this study.

Additional file 2. Statistic summary of sample characteristics. Table A1 presents the sample characteristics of the analytical sample in this study.

Additional file 3. Statistic summary of disability, work productivity and social participation by physical and mental conditions and gender. Table A2 presents the unadjusted mean or proportion of disability and productivity outcomes by type of multimorbidity.

Additional file 4. Association between multimorbidity and disability, work productivity and social participation, models including interactions between physical conditions and depression. Table A3 presents the results from the model that included interactions between number of physical chronic conditions and depression.

Additional file 5. Sensitivity analyses on the association between multimorbidity and productivity loss among different age groups. Table A4 presents the results of the sensitivity analyses on the association between multimorbidity and productivity loss using different samples. We repeated the analysis using a sample of respondents aged under 55 years, which is the mandatory retirement age for female white-collar workers. In addition, we used a cut-off at 65 years, given the possibilities that people may continue working after the mandatory retirement age.

\section{Abbreviations}

ADL: Activity of daily living; AOR: Adjusted odds ratio; CHARLS: China Health and Retirement Longitudinal Study; Cl: Confidence intervals; HICs: Highincome countries; IADL: Instrumental activity of daily living; LMICs: Low-and middle-income countries; NCDs: Non-communicable diseases

\section{Acknowledgements}

We gratefully acknowledge the China Health and Retirement Longitudinal Study team for providing data and training in using the datasets.

\section{Authors' contributions}

TP and JTL conceived and designed the study. SM provided important advice on study design. TP and YZ carried out the initial analysis. SM, BM and RA interpreted the data. YZ, AD and TP analysed the literature. TP and $J T L$ wrote the first draft of the paper. SM, YZ, BM, AD, RA and EH provided advice on the first draft and revised the article critically for important intellectual content. All authors reviewed and had final approval of the submitted and published versions.

\section{Funding}

No.

\section{Availability of data and materials}

The data that support the findings of this study are available in the [http:// charls.pku.edu.cn/index/en.html]. [The CHARLS] Yaohui Zhao, et al.; 2018; Harmonized CHARLS; the Gateway to Global Aging Data; Version C; http:// charls.pku.edu.cn/pages/data/harmonized_charls/en.html.

\section{Ethics approval and consent to participate}

This study used data from China Health and Retirement Longitudinal Study (CHARLS). Ethics is not required to analyse these data. The Biomedical Ethics Review Committee of Peking University approved CHARLS, and all participants were required to provide written informed consent. The ethical approval number was IRB00001052-11015.

\section{Consent for publication}

Not applicable.

\section{Competing interests}

The authors declare that they have no competing interests.

\section{Author details}

${ }^{1}$ Melbourne School of Population and Global Health, The University of Melbourne, 207 Bouverie Street, Melbourne, Victoria 3010, Australia. ${ }^{2}$ Usher Institute, College of Medicine and Veterinary Medicine, University of Edinburgh, Edinburgh, UK. ${ }^{3}$ The George Institute for Global Health at Peking University Health Science Center, Beijing, China. ${ }^{4}$ WHO Collaborating Centre on Implementation Research for Prevention \& Control of NCDs, Melbourne, Victoria, Australia. ${ }^{5}$ Harvard T.H. Chan School of Public Health, Harvard University, Cambridge, USA. ${ }^{6}$ Department of Primary Care and Public Health, School of Public Health, Imperial College London, London, UK.

Received: 15 July 2020 Accepted: 9 February 2021

Published online: 18 February 2021

\section{References}

1. GBD Causes of Death Collaborators. Global, regional, and national age-sexspecific mortality for 282 causes of death in 195 countries and territories, 1980-2017: a systematic analysis for the global burden of disease study 2017. Lancet. 2018:392(10159):1736-88.

2. Noncommunicable diseases. https://www.who.int/news-room/fact-sheets/ detail/noncommunicable-diseases. Accessed 1 May 2020.

3. Arokiasamy $P$, Uttamacharya $U$, Jain K, Biritwum RB, Yawson AE, Wu F, Guo $Y$, Maximova T, Espinoza BM, Rodriguez AS, et al. The impact of multimorbidity on adult physical and mental health in low- and middleincome countries: what does the study on global ageing and adult health (SAGE) reveal? BMC Med. 2015:13:178.

4. Academy of Medical Sciences: Multimorbidity: a priority for global research. 2018.

5. Afshar S, Roderick PJ, Kowal P, Dimitrov BD, Hill AG. Multimorbidity and the inequalities of global ageing: a cross-sectional study of 28 countries using the world health surveys. BMC Public Health. 2015;15:776.

6. Licher S, Heshmatollah A, van der Willik KD, Stricker BHC, Ruiter R, de Roos EW, Lahousse L, Koudstaal PJ, Hofman A, Fani L, et al. Lifetime risk and multimorbidity of non-communicable diseases and disease-free life expectancy in the general population: a population-based cohort study. PLoS Med. 2019;16(2):e1002741.

7. Zhang L, Ma L, Sun F, Tang Z, Chan P. A multicenter study of multimorbidity in older adult inpatients in China. J Nutr Health Aging. 2020; 24(3):269-76.

8. United Nations Department of Economic and Social Affairs: World population ageing 2017 - highlights (ST/ESA/SER.A/397). 2017.

9. Global Burden of Disease Compare. https://vizhub.healthdata.org/gbdcompare/. Accessed 1 May 2020.

10. Bao XY, Xie YX, Zhang XX, Peng X, Huang JX, Du QF, Wang PX. The association between multimorbidity and health-related quality of life: a cross-sectional survey among community middle-aged and elderly residents in southern China. Health Qual Life Outcomes. 2019;17(1):107.

11. Wang HH, Wang JJ, Wong SY, Wong MC, Li FJ, Wang PX, Zhou ZH, Zhu CY, Griffiths SM, Mercer SW. Epidemiology of multimorbidity in China and implications for the healthcare system: cross-sectional survey among 162,464 community household residents in southern China. BMC Med. 2014; $12: 188$

12. Zhao Y, Atun R, Oldenburg B, McPake B, Tang S, Mercer S, Cowling T, Sum G, Qin V, Lee JT. Physical multimorbidity, health service use and catastrophic health expenditure by socio-economic groups in China: a panel data analysis. Lancet Glob Health. 2020;8(6):e840-9.

13. Huang Y, Wang Y, Wang H, Liu Z, Yu X, Yan J, Yu Y, Kou C, Xu X, Lu J, et al. Prevalence of mental disorders in China: a cross-sectional epidemiological study. Lancet Psychiatry. 2019;6(3):211-24.

14. World Bank. Deepening health reform in China: building high-quality and value-based service delivery. Washington, D.C.: World Bank Group; 2016.

15. World Health Organization Regional Office for the Western Pacific. People's Republic of China health system review, vol. 5. Manila: WHO Regional Office for the Western Pacific; 2015.

16. Jing SS, Yin AT, Shi LZ, Liu JN. Whether new cooperative medical schemes reduce the economic burden of chronic disease in rural China. PLoS One. 2013;8(1):e53062.

17. Lee JT, Hamid F, Pati S, Atun R, Millett C. Impact of noncommunicable disease multimorbidity on healthcare utilisation and out-of-pocket expenditures in middle-income countries: cross sectional analysis. PLoS One. 2015;10(7):e0127199. 
18. Yip W, Fu H, Chen AT, Zhai T, Jian W, Xu R, Pan J, Hu M, Zhou Z, Chen Q, et al. 10 years of health-care reform in China: progress and gaps in universal health coverage. Lancet. 2019;394(10204):1192-204.

19. Wang J, Zhu H, Liu H, Wu K, Zhang X, Zhao M, Yin H, Qi X, Hao Y, Li Y, et al. Can the reform of integrating health insurance reduce inequity in catastrophic health expenditure? Int J Equity Health. 2020;19:49.

20. Read JR, Sharpe L, Modini M, Dear BF. Multimorbidity and depression: a systematic review and meta-analysis. J Affect Disord. 2017:221:36-46.

21. McLean G, Gunn J, Wyke S, Guthrie B, Watt G, Blane D, Mercer S. The influence of socioeconomic deprivation on multimorbidity at different ages: a cross-sectional study. Br J Gen Pract. 2014;64(624):e440-7.

22. Sum G, Hone T, Atun R, Millett C, Suhrcke M, Mahal A, Koh GC, Lee JT. Multimorbidity and out-of-pocket expenditure on medicines: a systematic review. BMJ Glob Health. 2018;3(1):e000505.

23. Wang L, Si L, Cocker F, Palmer AJ, Sanderson K. A systematic review of costof-illness studies of multimorbidity. Appl Health Econ Health Policy. 2018; 16(1):15-29

24. Demyttenaere K, Bonnewyn A, Bruffaerts R, Brugha T, De Graaf R, Alonso J. Comorbid painful physical symptoms and depression: prevalence, work loss, and help seeking. J Affect Disord. 2006:92(2-3):185-93.

25. Holden L, Scuffham $P$, Hilton M, Ware R, Vecchio N, Whiteford H. Healthrelated productivity losses increase when the health condition is comorbid with psychological distress: findings from a large cross-sectional sample of working Australians. BMC Public Health. 2011;11(1):417.

26. Ubalde-Lopez M, Arends I, Almansa J, Delclos GL, Gimeno D, Bultmann U. Beyond return to work: the effect of multimorbidity on work functioning trajectories after sick leave due to common mental disorders. J Occup Rehabil. 2017;27(2):210-7

27. Cabral GG, Dantas de Souza AC, Barbosa IR, Jerez-Roig J, Souza DLB. Multimorbidity and its impact on workers: a review of longitudinal studies. Saf Health Work. 2019;10(4):393-9.

28. Fouad AM, Waheed A, Gamal A, Amer SA, Abdellah RF, Shebl FM. Effect of chronic diseases on work productivity a propensity score analysis. J Occup Environ Med. 2017:59(5):480-5.

29. Zhao Y, Hu Y, Smith JP, Strauss J, Yang G. Cohort profile: the China health and retirement longitudinal study (CHARLS). Int J Epidemiol. 2014;43(1):61-8.

30. Liu DT-W. The effects of institutionalization in China: a difference-indifferences analysis of the mandatory retirement age. China Econ Rev. 2018; 52:192-203.

31. Zhao Y, Strauss J, Yang G, Giles J, Hu P, Hu Y, Lei X, Liu M, Park A, Smith JP et al: China health and retirement longitudinal study - national baseline users' guide. 2013 .

32. National Health and Family Planning Commission. Chinese citizens nutrition and chronic disease report 2015. Beijing: People's Medical Publishing House; 2015.

33. American Diabetes Association. 2. Classification and diagnosis of diabetes: standards of medical care in diabetes-2019. Diabetes Care. 2019; 42(Supplement 1):S13-28.

34. Xu Y, Wang L, He J, Bi Y, Li M, Wang T, Wang L, Jiang Y, Dai M, Lu J, et al. Prevalence and control of diabetes in Chinese adults. JAMA. 2013;310(9): 948-59.

35. Joint Committee for Guideline Revision. 2016 Chinese guidelines for the management of dyslipidemia in adults. J Geriatr Cardiol. 2018;15(1):1-29.

36. Zhang M, Deng Q, Wang L, Huang Z, Zhou M, Li Y, Zhao Z, Zhang Y, Wang L. Prevalence of dyslipidemia and achievement of low-density lipoprotein cholesterol targets in Chinese adults: a nationally representative survey of 163,641 adults. Int J Cardiol. 2018;260:196-203.

37. Strauss J, Lei X, Park A, Shen Y, Smith JP, Yang Z, Zhao Y. Health outcomes and socio-economic status among the elderly in China: evidence from the CHARLS pilot. Popul Ageing. 2010;3:111-42.

38. Hinterlong JE, Morrow-Howell N, Rozario PA. Productive engagement and late life physical and mental health: findings from a nationally representative panel study. Res Aging. 2007;29(4):348-70.

39. Liu H, Lou WQ. Patterns of productive activity engagement among older adults in urban China. Eur J Ageing. 2016;13(4):361-72.

40. Luo $Y$, Pan $X$, Zhang Z. Productive activities and cognitive decline among older adults in China: evidence from the China health and retirement longitudinal study. Soc Sci Med. 2019;229:96-105.

41. Buist-Bouwman MA, de Graaf R, Vollebergh WA, Ormel J. Comorbidity of physical and mental disorders and the effect on work-loss days. Acta Psychiatr Scand. 2005;111(6):436-43.
42. de Graaf R, Tuithof M, van Dorsselaer S, ten Have M. Comparing the effects on work performance of mental and physical disorders. Soc Psychiatry Psychiatr Epidemiol. 2012;47(11):1873-83.

43. Zhao Y, Zhang P, Oldenburg B, Hall T, Lu S, Haregu TN, He L. The impact of mental and physical multimorbidity on healthcare utilization and health spending in China: a nationwide longitudinal population-based study. Int J Geriatr Psychiatry. 2020. https://doi.org/10.1002/gps.5445.

44. Yao SS, Cao GY, Li M, Ai P, Huang Z, Xu BB. The prevalence and patterns of multimorbidity among community-dwelling older adults in China: a crosssectional study. Lancet. 2018;392:84.

45. Lu J, Lu Y, Wang X, Li X, Linderman GC, Wu C, Cheng X, Mu L, Zhang $\mathrm{H}$, Liu J, et al. Prevalence, awareness, treatment, and control of hypertension in China: data from 1.7 million adults in a populationbased screening study (China PEACE Million Persons Project). Lancet. 2017;390(10112):2549-58

46. Opoku S, Gan Y, Fu W, Chen D, Addo-Yobo E, Trofimovitch D, Yue W, Yan F, Wang Z, Lu Z. Prevalence and risk factors for dyslipidemia among adults in rural and urban China: findings from the China National Stroke Screening and prevention project (CNSSPP). BMC Public Health. 2019;19(1):1500.

47. Pan L, Yang Z, Wu Y, Yin RX, Liao Y, Wang J, Gao B, Zhang L. The prevalence, awareness, treatment and control of dyslipidemia among adults in China. Atherosclerosis. 2016;248:2-9.

48. Fields GS. Self-employment and poverty in developing countries. In: IZA world of labor 2019: 60v2. Germany: IZA; 2019.

49. Bennett J. Formality, informality, and social welfare. In: Discussion paper no 3550. Bonn: IZA; 2008.

50. Grawitch MJ, Waldrop JS, Erb KR, Werth PM, Guarino SN. Productivity loss due to mental- and physical-health decrements: distinctions in research and practice. Consult Psychol J Pract Res. 2017;69(2):112-29.

51. van Zon SKR, Reijneveld SA, Galaurchi A, Mendes de Leon CF, Almansa J, Bultmann U. Multimorbidity and the transition out of full-time paid employment: a longitudinal analysis of the health and retirement study. J Gerontol B. 2020;75(3):705-15.

52. Jindai K, Nielson C, Vorderstrasse B, Quiñones A. Multimorbidity and functional limitations among adults 65 or older, NHANES 2005-2012. Prev Chronic Dis. 2016:13:160174.

53. Scott KM, Von Korff M, Alonso J, Angermeyer MC, Bromet E, Fayyad J, de Girolamo G, Demyttenaere K, Gasquet I, Gureje O, et al. Mental-physical comorbidity and its relationship with disability: results from the world mental health surveys. Psychol Med. 2009:39(1):33-43.

54. The ESEMeD/MHEDEA investigators, Alonso J, Angermeyer MC, Bernert S, Bruffaerts R, Brugha TS, Bryson H, de Girolamo G, de Graaf R, Demyttenaere $K$, et al. Disability and quality of life impact of mental disorders in Europe: results from the European Study of the Epidemiology of Mental Disorders (ESEMeD) project. Acta Psychiatr Scand. 2004;109(s420):38-46.

55. Wells KB, Stewart A, Hays RD, Burnam MA, Rogers W, Daniels M, Berry S, Greenfield S, Ware J. The functioning and well-being of depressed patients: results from the medical outcomes study. JAMA. 1989;262(7):914-9.

56. Ormel J, Kempen GIJM, Deeg DJH, Brilman El, van Sonderen E, Relyveld J. Functioning, well-being, and health perception in late middle-aged and older people: comparing the effects of depressive symptoms and chronic medical conditions. J Am Geriatr Soc. 1998;46(1):39-48.

57. Schmitz N, Wang J, Malla A, Lesage A. Joint effect of depression and chronic conditions on disability: results from a population-based study. Psychosom Med. 2007:69(4):332-8.

58. Galenkamp H, Gagliardi C, Principi A, Golinowska S, Moreira A, Schmidt AE, Winkelmann J, Sowa A, van der Pas S, Deeg DJH. Predictors of social leisure activities in older Europeans with and without multimorbidity. Eur J Ageing. 2016;13(2):129-43.

59. Wels J. Assessing the impact of partial early retirement on self-perceived health, depression level and quality of life in Belgium: a longitudinal perspective using the Survey of Health, Ageing and Retirement in Europe (SHARE). Ageing Soc. 2018;40(3):512-36.

60. Eibich P. Understanding the effect of retirement on health: mechanisms and heterogeneity. J Health Econ. 2015;43:1-12.

61. Olesen SC, Butterworth P, Leach LS, Kelaher M, Pirkis J. Mental health affects future employment as job loss affects mental health: findings from a longitudinal population study. BMC Psychiatry. 2013;13:144.

62. Ubalde-Lopez M, Delclos GL, Benavides FG, Calvo-Bonacho E, Gimeno D. Measuring multimorbidity in a working population: the effect on incident sickness absence. Int Arch Occup Environ Health. 2016;89(4):667-78. 
63. Troelstra SA, Straker L, Harris M, Brown S, van der Beek AJ, Coenen P. Multimorbidity is common among young workers and related to increased work absenteeism and presenteeism: results from the population-based Raine study cohort. Scand J Work Environ Health. 2020;46(2):218-27.

64. Bertram MY, Sweeny K, Lauer JA, Chisholm D, Sheehan P, Rasmussen B, Upreti SR, Dixit LP, George K, Deane S. Investing in non-communicable diseases: an estimation of the return on investment for prevention and treatment services. Lancet. 2018;391(10134):2071-8.

65. Sun J, Buys N, Wang XC. Effectiveness of a workplace-based intervention program to promote mental health among employees in privately owned enterprises in China. Popul Health Manage. 2013;16(6): 406-14.

\section{Publisher's Note}

Springer Nature remains neutral with regard to jurisdictional claims in published maps and institutional affiliations.

Ready to submit your research? Choose BMC and benefit from:

- fast, convenient online submission

- thorough peer review by experienced researchers in your field

- rapid publication on acceptance

- support for research data, including large and complex data types

- gold Open Access which fosters wider collaboration and increased citations

- maximum visibility for your research: over $100 \mathrm{M}$ website views per year

At BMC, research is always in progress.

Learn more biomedcentral.com/submissions 